\title{
STUDIES ON THE BEHAVIOUR OF SOME IONS IN THE HEART OF RATS INFECTED WITH TRYPANOSOMA BRUCEI BRUCEI
}

\author{
'Adedosu, O. T., ${ }^{2}$ Olowe, O. A., ${ }^{1}$ Adekunle, A. S., 'Olaiya, C.O. \\ ${ }^{1}$ Department of Biochemistry, College of Health Sciences, \\ P.M.B. 4000, LAUTECH Ogbomoso \\ ${ }^{2}$ Department of Medical Microbiology and Parasitology \\ College of Health Sciences P.M.B. 4400, LAUTECH Osogbo
}

Correspondence to: O. T. Adedosu

\begin{abstract}
Behaviour of Sodium $\left[\mathrm{Na}^{+}\right]$, Potassium $\left[\mathrm{K}^{+}\right]$and Phosphorous $\left[\mathrm{PO4}^{s}\right]$ ions was studied in the heart of albino rats infected with Trypanosoma brucei brucei and the parasitaemia level monitored. Post infection shows a significant rise [p $<0.05$ ] in $\mathrm{Na}^{+}, \mathrm{K}^{+}$, and $\mathrm{Ca}^{2+}$ ions concentration with a significant de crease $(p<0.05)$ in the phosphorous ions concentration as the disease progresses. At high parasitaemia level, there is a slight increase in $\mathrm{Na}^{+}$and $\mathrm{PO}^{3}$ ions while $\mathrm{K}^{+}$concentration remains constant and $\mathrm{Ca}^{2+}$ ions concentration was significantly reduced $(p<0.05)$. The reasons and mechanism responsible for these are unknown although their increased concentrations in tissues generally have been shown to be as a result of damage to celis and tissues during infection.
\end{abstract}

Key words: Trypanosoma brucei brucei, Parasitaemia level, Concentration of ions.

\section{INTRODUCTION}

Some ions such as sodium, potassium and calcium have been discovered to be the most important components of extra-cellular and intracellular fluids of most tissues in animal. They are involved in various phisiological roles and their concentrations in pathological states of animals have served as a good parameter in clinical diagnosis especially in Trypanosoma $b$. brucei infection where for example the parasite infectivity potential and toxicological effects have been based on maintenance of calcium 
homeostasis $(1,2,3)$.

With a unique ability to maintain the cellular contents and ions stable concentrations, Trypanosoma $b$. brucei, to which humans have become refractory on the basis of a high density lipoprotein that is toxic to the parasites, ravages cattle and sheep over millions of square miles in Africa (1). Although, these ions have been established as necessary requirement by the infecting parasite, their concentrations in the host are equally affected during intection.

\section{MATERIALS AND METHODS}

Seventeen Albino rats (Rattus norvegicus) of mixed sexes weighing between 200-300g obtained from animal house, Biochemistry Department, University of Ilorin were used for this work. These were randomly selected into three groups: uninfected (control), infected (test) and infected but used to monitor the parasitaemia level.

The parasite strain (ILRAD 1807 maintained in monkey host) were obtained from the Veterinary Pathology Department, University of Ibadan and used for inoculation of rats with phosphate saline glu- cose (PSG). This serves as a buffer for keeping the trypanosome alive and to dilute the parasitaemia level obtained from the rat blood samples to 2-5 trypanosome per view, which was used to inoculate the animal intra peritoneally with syringe containing $0.5 \mathrm{ml}$ of the inoculum. Feeding and other sanitary conditions were maintained as it was before inoculation. Parasitaemia level was observed on daily basis through blood smears.

Animals were anaesthesized with chloroform and sequentially sacrificed every other day. Organs were then collected after sacrificing the animal and placed in $0.25 \mathrm{M}$ sucrose solutions for homogenization using pestle and mortar for subsequent analysis for sodium, potassium, calcium and phosphorous ions in the heart.

Cations determination in heart homogenate was carried out by flame photometry for $\mathrm{Na}^{+}$and $\mathrm{K}^{+}$ based on the principle that these ions emit light when aspirated into a burner. The light emitted passes through a filter into a photosensitive element to produce currext. The amount of current produced is proportional to the concentration of the ions in the sample. The calcium 
iuns were determined by complexometric method (4). Calcium reacts with cresophthalein comphexone in alkaline medium to give a purple colour, which is estimated colorimetrically at $580 \mathrm{~nm}$. Phosphorus ions in heart homogenates were determined by the method of Fisher and Subbarows (5). Phosphate reacts with acid molybdate to form phosphomolybdic acid. The hexavalent molybdenum of the phosphomolybdic acid then react with malachite green (reducing agent) to give a green colour read at $620 \mathrm{~nm}$, the intensity of which is proportional to the concentration of phosphate ions present in the sample

\section{RESULT}

The parasitaemia level as infection progresses is shown in Fig 1. Day 0 represents the day inoculation was done. The pre-patent period was approximately 48 hours, an objective measurement susceptible to experimental analysis (6). The graph is an indication of alternating rise and fall in parasitaemia level until eventual death of the animal. Fig 2, 3, and 4 shows the level of sodium, potassium and calcium ions concentration in the heart homogenate upon infection. The results shows significant rise $(p<0.05)$ in the ion concentration while this is followed by fluctuations in the levels until the eventual death of the animal. Fig. 5 shows phosphorus ions concentration in the heart homogenate with a significant decrease $(p<0.05)$ in its concentration followed by a period of increased level and eventual fluctuation in concentration. 


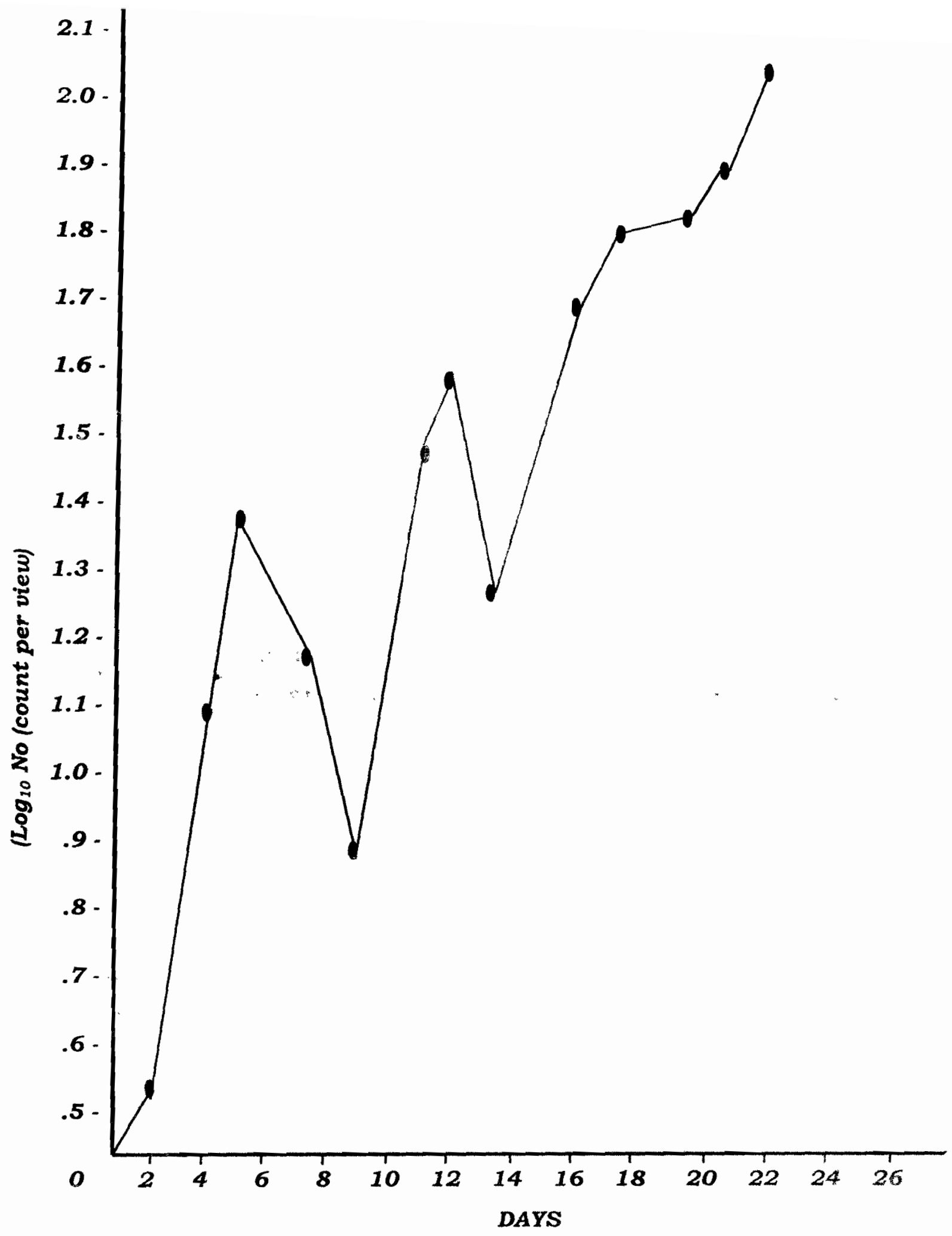

Fig. 1: A Plot of parasitaemia level as disease progress 


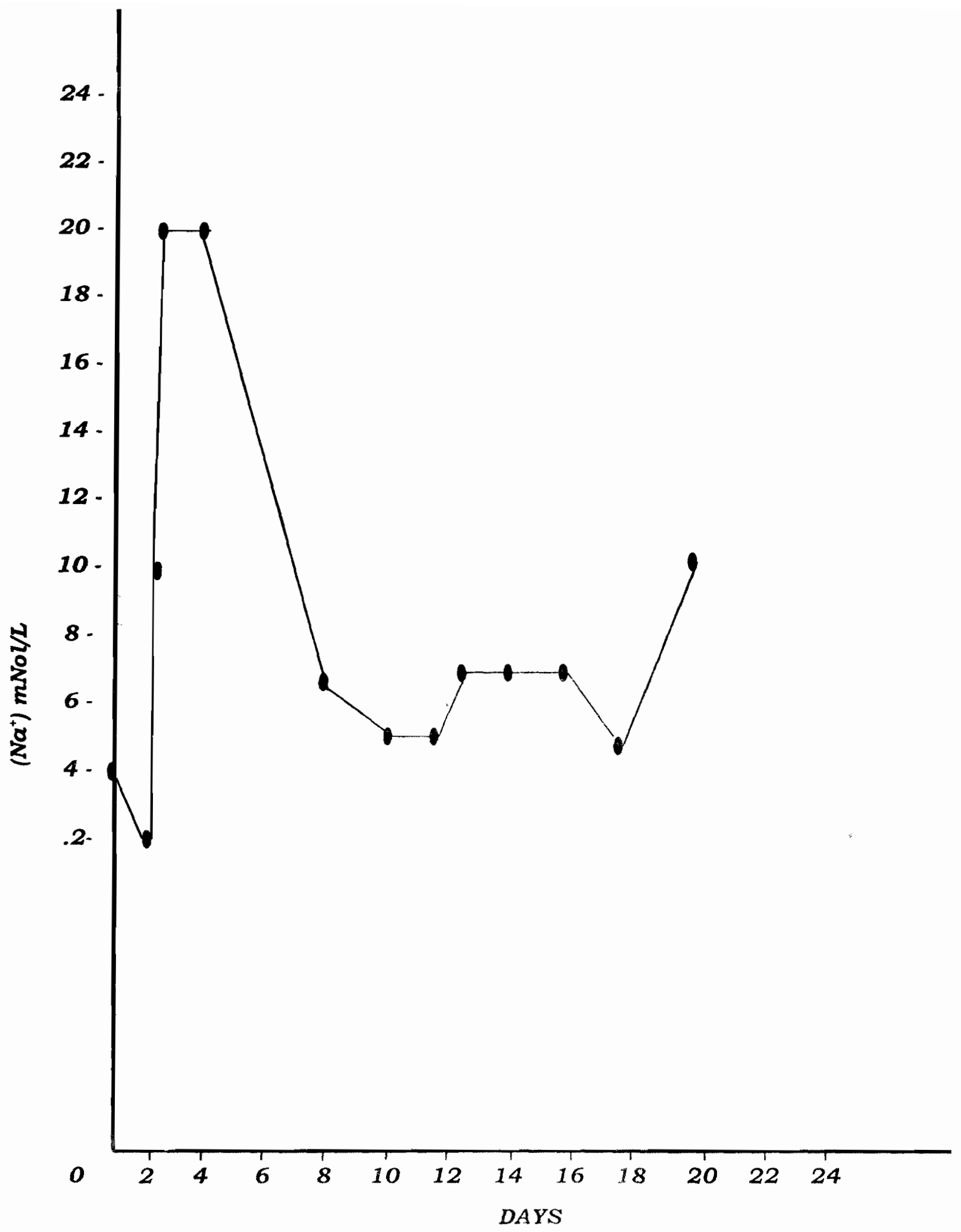

Fig. 2: Sodium ion concentration in heart during Try sunosome infection in rats 


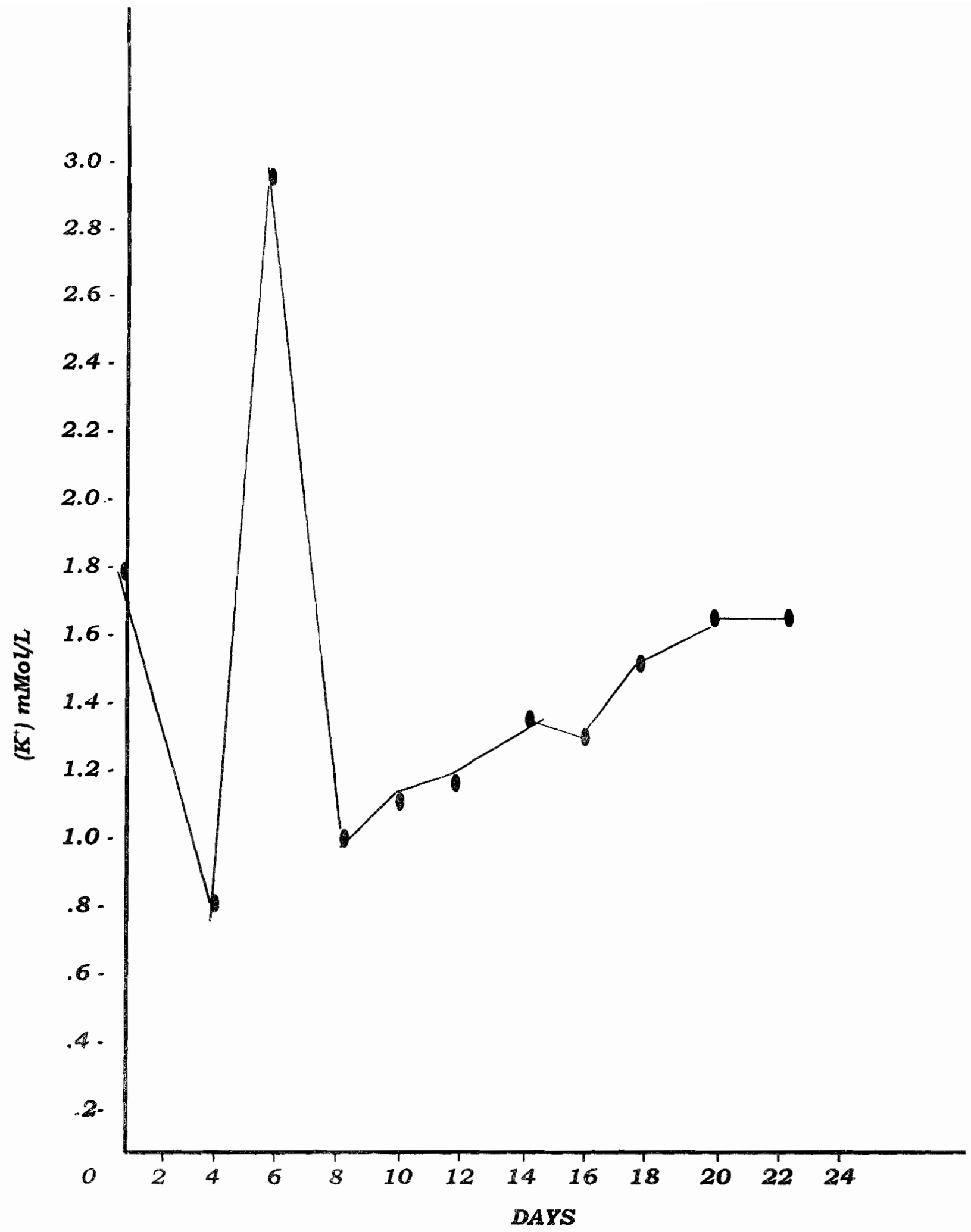

Fig. 3: Potassium ion concentration in heart During Trypanosome infection in rats. 


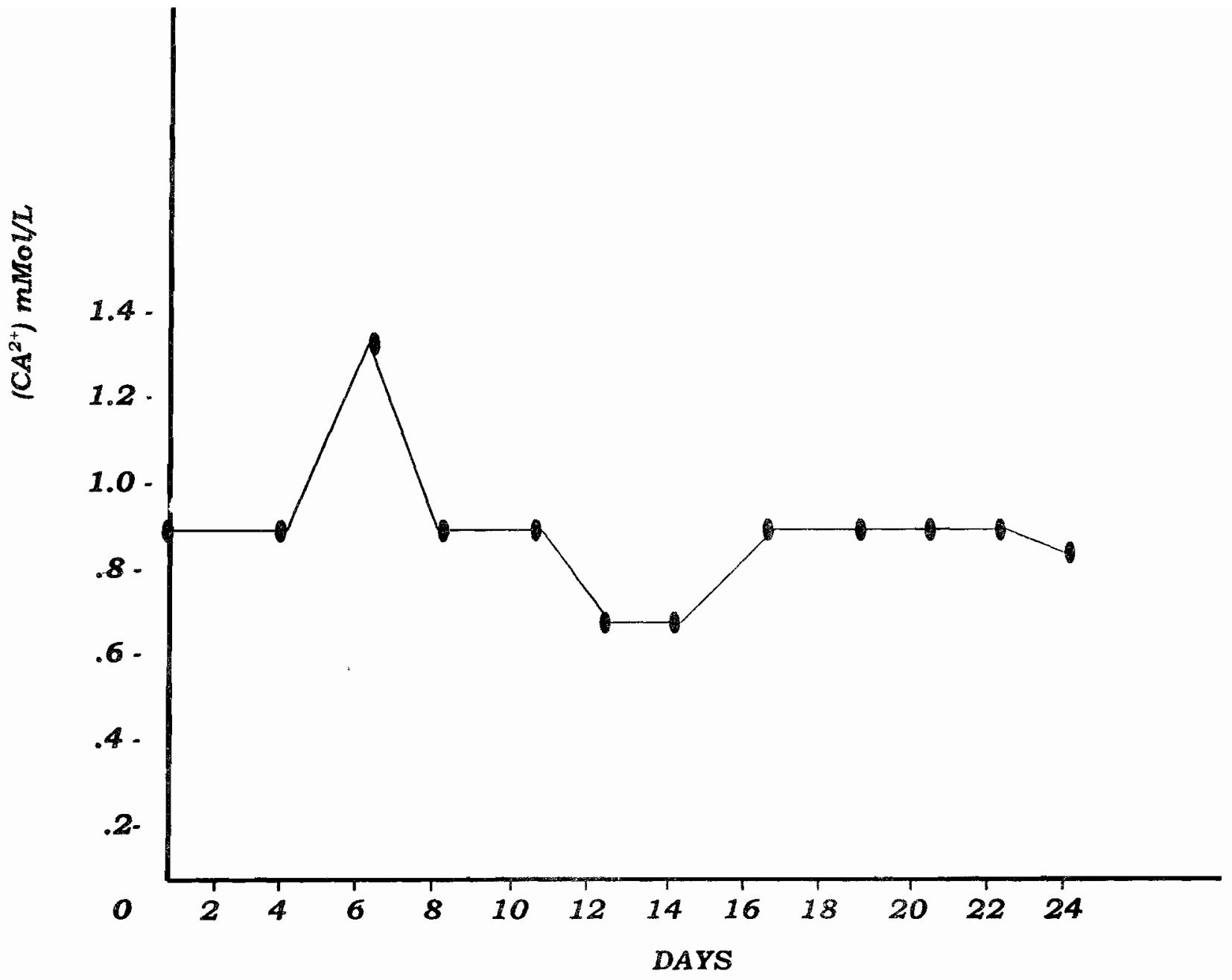

Fig. 4: Calcium ion concertration in heart During Trypanosome infection in rats. 


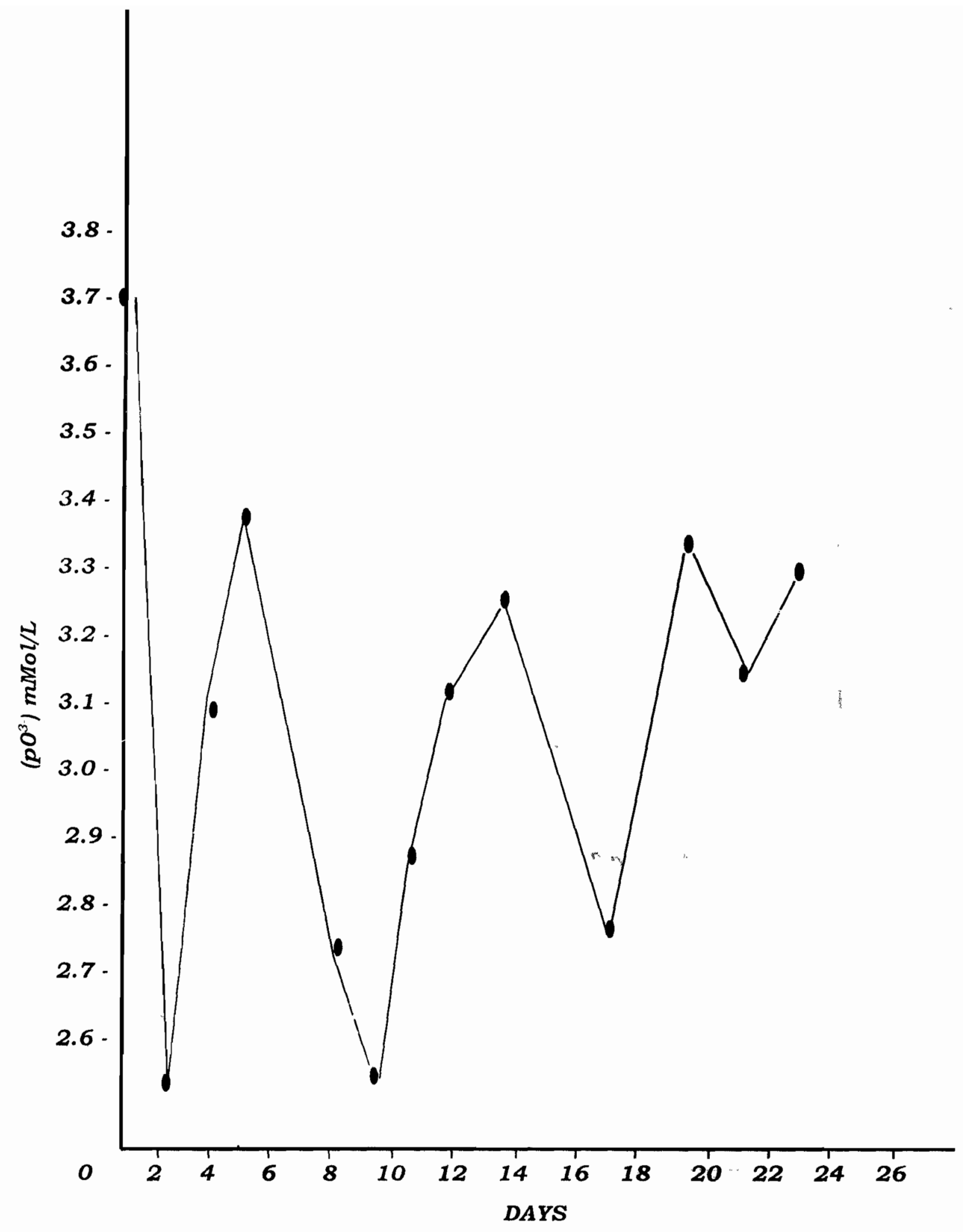

Fig. 5: Phosphorus ion concentration in heart During Trypanosome infection in rats. 


\section{DISCUSSION}

The parasitaemia level as monitored on daily basis in Fig 1 after the pre patent period shows a significant increase in the first few days of infection and this is followed by periods of fluctuations and remissions in which the parasite population were decreased. This decrease might have been due to the production of antibodies, which suppresses further production of the trypanosomes. However after this initial stage, a significant rise $(p<0.05)$ in parasitaemia level was noted leading to the death of the animals. This is probably due to the immune evasion mechanism of the parasites, which renders the immune response to earlier generation of trypanosomes ineffective $(1,10)$

The significant rise $(p<0.05)$ of $\mathrm{Na}^{+}, \mathrm{K}^{+}$and $\mathrm{Ca}^{2+}$ ions concentration shown graphically post infection is an indication of damages done to the cells and tissues of the hos1 being infected by trypanosomes $(7,8)$. The decrease and fluctuations in concentration of these ions as the disease progresses may be explained by the antigenic variation property of the parasite in which as variants of the parasite are being destroyed by the host, others undergo a genetic rearrangements to escape the host immune system for a while usually through changes in membrane components in successive generations. The consequent response of the host immune system on recognizing these variants leads to killing of these parasites due to its earlier stimulation by the parasite (1).

At high parasitaemia level with consequent death of the animal, $\mathrm{Na}^{+}$and $\mathrm{PO}^{3-}$ ions were not significantly increased while $\mathrm{K}^{+}$ions remain constant as $\mathrm{Ca}^{2+}$ ions concentration also decrease. The reasons responsible for these were unknown, although calcium ions have been shown to have influence on the cytoskeleton and morphology of the nucleolus in $T$. b. brucei (9). This study has shown the need to understand the basis and mechanisms responsible for behaviour of these ions during infection by $T . b$. brucei, which can be used as clinical parameters for diagnosis in higher animals. 


\section{REFERENCES}

1. Cotran RS, Kumar V, Collins $T$ (eds.). Robbins Pathologic basis of disease, $6^{\text {th }}$ ed, Philadelphia, WB Saunders Co, 1999: $343-346$.

2. Morenos SNJ, Decampo R, Vercesi AE. Calcium homeostasis in procyclic and blood stream of forms of $T$. brucei. J. Biol. Chem. 1992; 267: 6020-6026.

3. Xiong $Z \mathrm{H}$, Ridgley EL, Enis D, Olness F, Ruben L. Selective transfer of calcium from acidic components to the mitochondrion of Trypanosoma brucei: Measurement with target Aquarians. J. Biol. Chem. 1997; 272: 3102231028

4. Baginski ES, Marie SS, Clark WL, Zak B. Direct microdetermination of serum calcium: Clinchima. 1973; 48 (1): $49-54$.

5. Fisher and Subbarows. Principle and Techniques of Practical Biochemistry. 4th edition. Cambridge University Press. 1994: 140-141.
6. Mulligan HW. Clinical manifestation and diagnosis " of sleeping sickness. The African trypanosomiasis. London. Allen and Unwin $661-683$.

7. Andrew SJ, Johnson C, Mand Dormal VJ. Lethal factors in experimental injection with trypanosomes in rats; $A m$. J. Hyg. 1930; 12: $381-400$.

8. Obioma Nwaorgu, Moses OE, Okpala I, Okpala IC. Studies on the histopathology of $T$. brucei in albino rats. 1981; 2 (1\&2): 15-30.

9. Selzer PM, Webster P, Duszeniko $M$. Influence of calcium depletion on cytoskeleton and nucleolus morphology in Trypanosoma brucei. Eur. J. Cell. Biol. 1991; 56 (1): $104-112$.

10. Donald WM, Stewart J. Immunology, $8^{\text {th }}$ edition. 1997:156 - 157 . 